\title{
Flare Gas Gathering and Utilization: A Strategic Approach to Greenhouse Gas Emission Reduction in Nigeria
}

\author{
Yobo Moses Tambari ${ }^{1}$, Sornaate Lucky Easy ${ }^{2}$, Akpan Paul Paulinus ${ }^{2}$ \\ ${ }^{1}$ Ministry of Education, Port Harcourt, Nigeria, West Africa \\ ${ }^{2}$ Department of Civil Engineering, Ken Saro-Wiwa Polytechnic, Rivers State, Bori-Ogoni, Nigeria, West Africa
}

\section{Email address:}

tambari.moses@gmail.com (Y. M. Tambari),goldeasydaddy@gmail.com (S. L. Easy), paulynciap06@yahoo.com (A. P. Paulinus)

\section{To cite this article:}

Yobo Moses Tambari, Sornaate Lucky Easy, Akpan Paul Paulinus. Flare Gas Gathering and Utilization: A Strategic Approach to Greenhouse Gas Emission Reduction in Nigeria. International Journal of Environmental Protection and Policy. Vol. 4, No. 1, 2016, pp. 10-15. doi: 10.11648/j.ijepp.20160401.12

\begin{abstract}
Apart from contributing to greenhouse gas emission, flared gases create trade-off emissions such as carbon (iv) oxide $\left(\mathrm{CO}_{2}\right)$, methane $\left(\mathrm{CH}_{4}\right)$, nitrogen oxides $\left(\mathrm{NO}_{\mathrm{X}}\right)$, sulphur oxides $\left(\mathrm{SO}_{\mathrm{X}}\right)$ and water vapour. The impact of such flared gases is of both local and global concern. Therefore, the purpose of the present study is to review current literature on gas gathering and utilization and to determine the most efficient and economic means of harnessing flared gases in order to contribute to the attainment of the "no routine flare" policy of government and reduce greenhouse gas emission. In this paper, analysis is made of energy and gas flaring trends in Nigeria by examining available data with a view to understanding the possible impact of the recovered gas on gas supply in the country. A comparison of traditional gas gathering technologies to gas ejector technology is also made. This study found that despite efforts to reduce gas flaring in Nigeria, about 81\% of gas flared in the last 6 years is from Service Contract (SC), Sole Risks/Independent (SR/I) and Marginal Fields (MF) companies most likely because of the high cost of investment in gas gathering utilities and lack of market for gas and gas products. Thus, this paper identifies gas ejector technology as a viable compression equipment to cut compression costs. Given the current excess gas capacity of the country and the Nigerian power market which is currently undersupplied and generates significant greenhouse gases (GHGs), this paper recommends the use of the recovered flare gas for power generation, which will not only directly help to reduce Nigeria's contribution to GHG emission from flaring, but also substantially help to cut down her overall emission level mainly from the industrial use of fossil fuel for power generation and wood fuel for heating.
\end{abstract}

Keywords: Gas Ejector, Gas Gathering, Greenhouse Gas Emission, Flare Gas, Climate Change

\section{Introduction}

The emission of greenhouse gases (GHGs) especially carbon dioxide $\left(\mathrm{CO}_{2}\right)$ has been reported to be the major factor behind recently observed changes in climate extremes such as storms, floods, and heat waves as well as increasing global temperatures and rising sea levels. Gas flaring impacts climate change by adding about 400 million tons of $\mathrm{CO}_{2}$ in annual emissions [1]. In Nigeria, gas flaring has been a major means through which green houses gases (GHGs) are released into the atmosphere. Carbon dioxide emissions especially in the Niger Delta are among the highest in the world [2].

Though the emission level in Nigeria is not so significant on a global scale, however, international cooperation is required to effectively mitigate GHG emissions and address other climate change issues [3]. Thus, a number of efforts targeted at zero routine gas flaring have been made including the Federal Government's "no routine flare" deadline of December 2010 (which was not achieved), expansion of the local gas market via the National Independent Power Projects (NIPP) and the development of Associated Gas Gathering (AGG) Projects for gathering associated gas to a processing and treatment facility or gas pipeline system.

Despite these efforts, flaring has continued in the country. The main challenges amongst others include:

- The variable volume and low pressure (usually near atmospheric) of separated associated gas due to significant pressure reduction in the separators in order to achieve maximum oil recovery and stabilisation.

- The cost of compression requirement for gathering these low pressure gases for flaring reduction projects especially for marginal fields and 
- The lack of gas and gas products market given the already surplus gas capacity of the country.

Therefore, this research work is a review of current literature on the application of gas ejectors (claimed to be economical for pressure recovery) to the recovery of marginal and low pressure (LP) flared gases in order to reduce GHG emissions, improve sustainable development and increase revenue.

\section{Literature Review of Crude Oil Processing}

Petroleum reservoirs contain natural gas formed as a gas cap trapped between the petroleum and an impervious capping rock layer. Under the very high pressure conditions usually found in the reservoir, the gas is mixed with or dissolved in the crude oil (known as associated gas) and always accompany oil production as a by-product.

During oil production at the production platform, the reservoir fluid (oil, gas, water and sediments) flows out into the well-bore and is channelled into production separators located at the flow station to remove high and low pressure gases from the oil [4]. On leaving the production separators, the oil and the remaining gas in solution is directed to the surge tank where the gas remaining in oil is separated near sea level pressure [5]. The separated gas collected from the top of the surge vessel is a LP gas resource. Figure 1 is an overview of the oil production process.

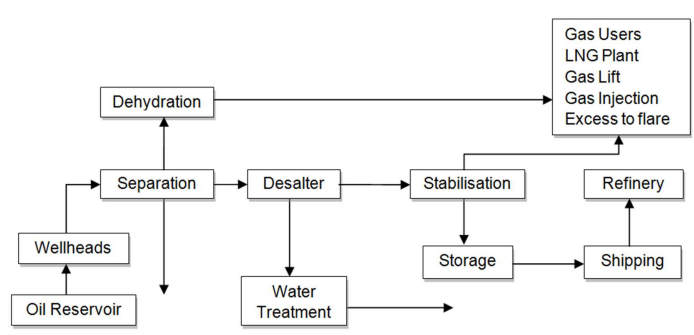

Figure 1. Typical crude oil production overview.

To achieve maximum liquid recovery and stabilized oil and gas, and separate water, the pressure of the reservoir fluid is often reduced in several separation stages (high pressure separator, low pressure separator, etc.) resulting in a low pressure gas from the last stage of separation (usually called surge vessel or low pressure (LP) separator), because a large pressure reduction in a single separator will cause flash vaporization leading to instabilities and safety hazards [6]. Thus, the produced gas from the separators usually at low pressure near atmospheric requires compression in order to be transported to the consumer via a gathering line or liquefaction; else it is sent to the flare.

\section{Materials and Methods}

The material used for this research is Gas Ejector System. The method adopted in the analysis involves operational principles of a gas jet ejector, best approach to flare gas recover, gas production and utilization in Nigeria was presented and compared using standard table and graph.

\subsection{Gas Ejector System}

Traditional gas compression technologies being applied to associated gas recovery is very costly especially for a low pressure gas resource with variable volume. Thus, increased interest in fuel conservation, waste heat utilization, and cost reduction has stimulated recent upsurge in the use of gas ejectors as alternative boosting system especially in the natural gas industry.

The use of gas ejectors in upstream oil and gas production has been increasing in the past decade due to development work to improve their performance and efficiency and the adoption of robust designs to meet the stringent requirements of the oil and gas industry. The key factors which affect the attractiveness of these systems are the maximum use of the available energy in each field or platform, simplicity, reliability and low capital cost which make them ideal for marginal fields which cannot afford the high capital and operational costs of alternative boosting systems. Gas ejectors have been used in applications for the recovery of flare gases, oil well production boosting, subsea processing, and sand slurry pumping [7]. A typical ejector configuration is shown in Fig. 2 and comprises of a nozzle, mixing chambers and a diffuser.

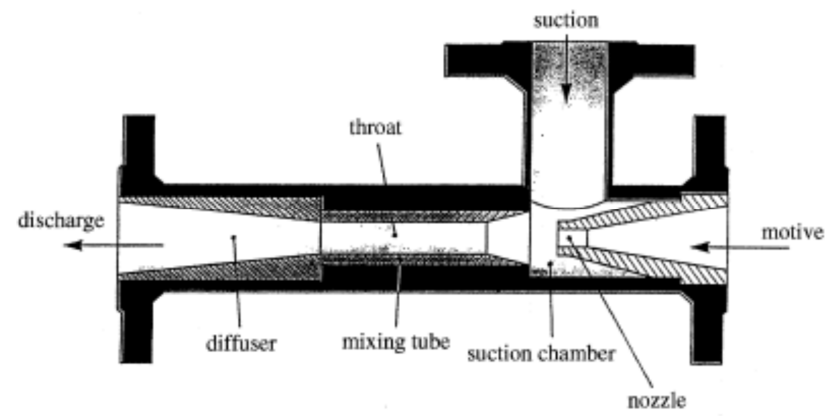

Figure 2. Configuration of Gas Jet Ejector (Sacha, et al, 2006).

\subsection{Operational Principles of a Gas Jet Ejector}

High pressure natural gas from a fuel gas system or high pressure separator is commonly used as the source of motive gas. Conversion of pressure energy into velocity takes place when the motive gas accelerates and expands while passing through the convergent/divergent nozzle. The velocity of the gas is increased substantially in the primary nozzle to produce a supersonic flow, which creates a low pressure zone at the mixing chamber - lower than the suction pressure of LP gas. The partial vacuum created by the supersonic primary flow entrains the suction gas through momentum transfer. Both gases are then mixed in the mixing chamber and enters a normally choked (sonic flow conditions) at the throat. The flow expands in the diffuser part of the nozzle through a thermodynamic shock process, which results in a sudden rise of the static pressure. The flow emerges from the 
shock wave with subsonic velocity and pressure recovery. The mixture is further compressed in the diffuser to an intermediate pressure level between HP and LP pressures.

\subsection{Approach to Flare Gas Recovery}

A 2-stage gas ejector system designed to suck the low pressure (LP) and surge vessel (SV) gases is installed after the LP and SV separators respectively (fig. 3) to compress the SV gas to LP gas and LP gas to HP, which will meet the pipeline sale gas pressure of 70 bars. The discharge gases from the SV and LP ejector is refluxed to their respective suction streams to help accommodate changes in process gas condition.

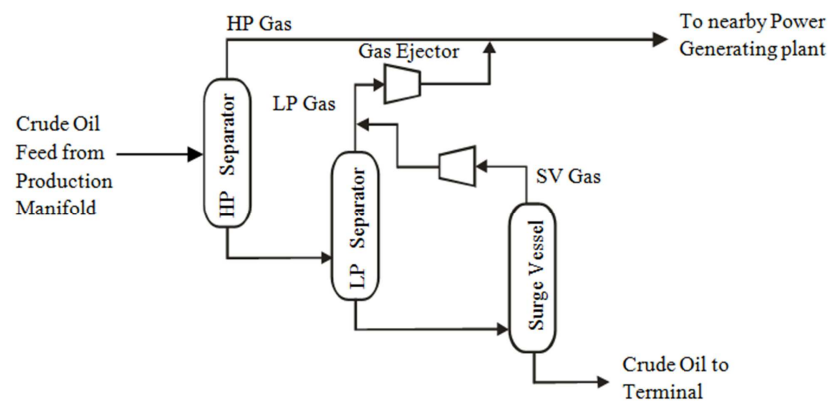

Figure 3. Flare Gas recovery Scheme.

The gas ejector system uses high pressure motive gas from the compressor turbine stream of the fuel gas system. This ensures that the pressure of the motive gas is fairly stable.

\section{Results and Discussion}

Gas production and utilization in Nigeria extracted from NNPC Annual Statistical Bulletin, 2000-2013, the Nigeria gas market and alternatives for gas utilization are presented. The design and performance of gas injector system is also discussed.

\subsection{Gas Production and Utilisation in Nigeria (2000-2013)}

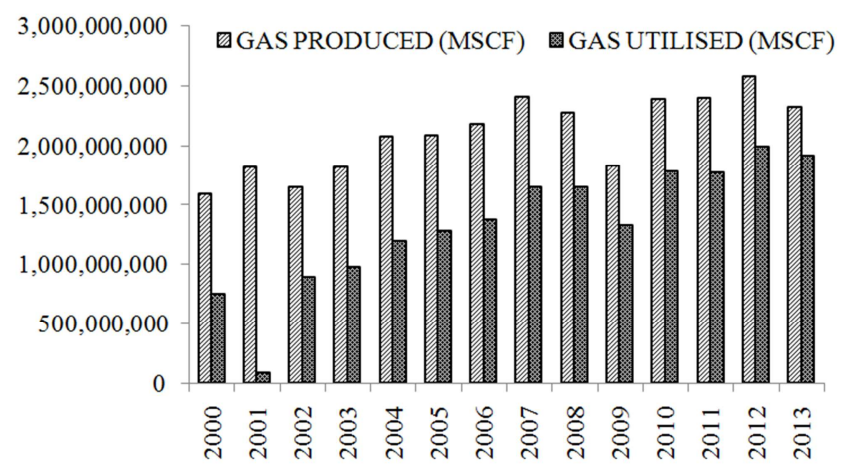

Figure 4. Gas Production in Nigeria (2000-2013)*.

When crude oil production started in 1958 , the quantity of associated gas produced along with it was considered insignificant and apart from a small proportion used to run some equipment and facilities, majority of the gas produced was flared. Over the years, there has been a growing utilisation of natural gas in the country (figure 4).

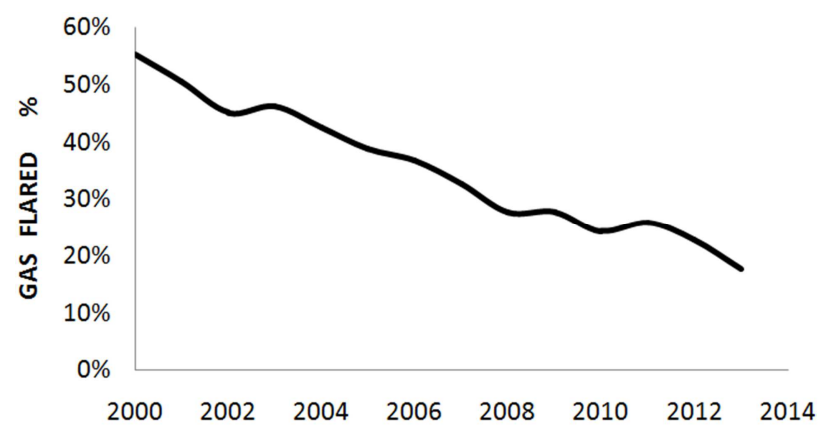

Figure 5. Trend in Gas Flaring (2000-2013)*.

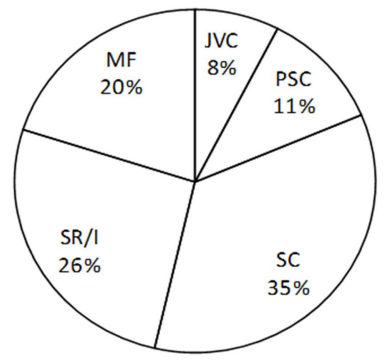

JVC - Joint Venture Companies

PSC - Production Sharing Contract

$\mathrm{SC}$ - Service Contracts

SR/I - Sole Risks/Independent

MF - Marginal Fields

Figure 6. Average Gas Flaring by Company Type (2009-2013)**.

*: Based on data extracted from NNPCAnnual Statistical Bulletin, 20002013 See Appendix III.

**: Based on data extracted from NNPCAnnual Statistical Bulletin, 20002013 See Appendix III.

Figure 5 indicates that gas flaring in the country has greatly reduced. However, the amount of gas flared by service contract (SC), Sole Risk/Independent (SR/I) and Marginal Fields (MF) companies have not changed much. Apart from the use of produced gas for fuel, the only other use of the produced gas by these companies was for sale to third parties (NNPC ASB, 2009-2013). The cost of investment in gas gathering equipment may be a big contributing factor.

\subsection{The Nigeria Gas Market}

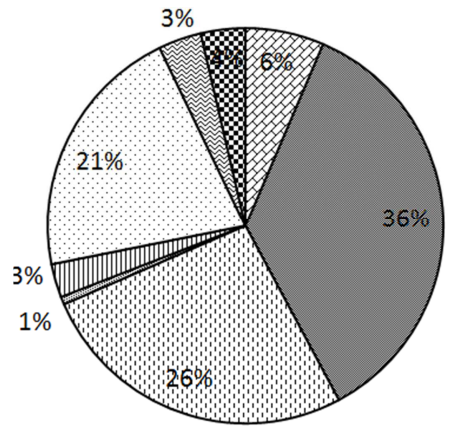

\author{
๑GASUSED AS FUEL \\ (MSCF) \\ 口GAS SOLD TO THIRD \\ PARTY (MSCF) \\ ĐGASRE-INGECTED \\ (MSCF) \\ $\square$ GASTO EPCL (MSCF)
}

Figure 7. Percentage Gas Utilisation (2000-2013)*.

* Based on data extracted from NNPC Annual Statistical Bulletin, 20002013 See Appendix I and II.

The above figure shows that there exist a significant 
opportunity for investment in the use of recovered gas for power generation. Accordingly, the most gas at the period under review has been used by third parties especially

industries for independent power projects.

\subsection{Alternatives for Gas Utilisation}

Table 1. Gas Development Options (Harison, 1984).

\begin{tabular}{lllll}
\hline & LPG Plant & Gas cycling & Power Generation & LNG \\
\hline Product & LPG condensate & Re-injection & Electricity & Liquefied Methane \& ethane \\
\hline Threshold field size to feedstock (BCF) & $300-400$ & $250-400$ & 650 & 5000 \\
Minimum feed (mcf/d) & $60-80$ & $40-75$ & 85 & $385 /$ train \\
\% produced a year of project life & $5-10 \%$ & $7 \%$ & $3 \%$ & $4 \%$ \\
Project life (years) & $10-20$ & 13 & 20 & 25 \\
Capacity & $60 \mathrm{mcf} / \mathrm{d}$ & $30 \mathrm{mcf} /$ day & $500 \mathrm{MW}$ & 5.5 min tonnes/year \\
Markets & Local, export & Local & Local, grid needed & Export \\
Plant location & Local, Port city & Local & Local & Port city \\
Plant capital cost (SM) & $50-60$ & $75-100$ & $350-400$ & $2,500-3,000$ \\
Lead time & $>3$ years & $>2-3$ years & $>1$ year & $>7-10$ years \\
\hline
\end{tabular}

While the increasing potential for liquefied natural gas (LNG) or gas-to-liquid (GTL) will help to alleviate the problem of lack of market for gas products, it will likely not be economically feasible for at least 3 more years (Table 1). Only the use of gas for power generation has the shortest lead time ( $>1$ year) and a large growing market (Fig 6).

\subsection{Design and Performance}

Although, it is generally reported to have low efficiency, recent research has helped to significantly improve its performance. Motive: suction expansion pressure ratio of 14.0 and compression (discharge: suction) pressure ratio of 8.1 is reported as optimum design [9]. Its design incorporates robust material selection that could withstand the hash process conditions of natural gas applications. The use of changeable nozzle and diffuser allows for flexibility when process condition changes.

Replacing the traditional boosting system with the ejector will result in significant savings in capital expenditure (CAPEX) and operational expenditure (OPEX). The capital cost of the ejector is much less compared to available traditional gas boosting technologies; maintenance cost is highly reduced (no moving parts), making the gas ejector highly available - attractive for remote installations. The ejector does not require any external source of power supply, rather it uses high pressure motive gas stream usually available in production platform thus, cutting down the cost of power generation. High amount of heat of integration is available for use in other applications. Above all, emissions of greenhouse gases are eliminated.

\section{Conclusion}

As observed in figure 5 above, most gas is still being flared by Service Contract (SC), Sole Risks/Independent (SR/I) and Marginal Fields (MF) companies (about $81 \%$ of gas flared in the last 6 years) most likely because of the cost of investment in gas gathering utilities. The use of gas ejectors in the recovery of flared gases will not only reduce process costs but will also help to reduce the capital costs and cost of power for these companies.

Given the short lead time for power generation project construction, and the large growing domestic market (current power generation capacity of about $4000 \mathrm{MW}$ way too small for a population of about 150 million people), the use of the recovered gas for power generation is a short term strategy that will not only help to reduce GHG emission (especially from the increased use of private generators popularly called "pure water generator", diesel generators for industrial power generation with its attendant noise and air pollution, and wood fuel (of higher carbon content) for heating and other purposes), but will also result in increased revenue from sale of recovered flare gas and enhance sustainable development.

\section{Appendix I}

Table 2. Gas Production in Nigeria 2000-2013.

\begin{tabular}{|c|c|c|c|c|c|c|}
\hline YEAR & $\begin{array}{l}\text { GAS PRODUCED } \\
\text { (MSCF) }\end{array}$ & $\begin{array}{l}\text { GAS USED AS } \\
\text { FUEL (MSCF) }\end{array}$ & $\begin{array}{l}\text { GAS SOLD TO } \\
\text { THIRD PARTY } \\
\text { (MSCF) }\end{array}$ & $\begin{array}{l}\text { GAS RE- } \\
\text { INGECTED } \\
\text { (MSCF) }\end{array}$ & $\begin{array}{l}\text { GAS TO EPCL } \\
\text { (MSCF) }\end{array}$ & $\begin{array}{l}\text { FEEDSTOCK GAS } \\
\text { FOR NGL/NGL TO } \\
\text { EPCL (MSCF) }\end{array}$ \\
\hline 2000 & $1,598,950,233$ & $78,410,897.00$ & $13,817,884.00$ & $299,737,926.00$ & $7,174,416.00$ & $23,060,743.00$ \\
\hline 2001 & $1,822,922,111$ & $94,038,772.00$ & & & & \\
\hline 2002 & $1,651,591,488$ & $71,895,558.00$ & $101,619,643.00$ & $270,402,167.00$ & $9,159,870.00$ & $47,721,060.00$ \\
\hline 2003 & $1,828,541,855$ & $66,234,516.00$ & $85,871,813.00$ & $187,246,149.00$ & $9,037,946.00$ & $36,046,246.00$ \\
\hline 2004 & $2,082,283,189$ & $71,534,048.00$ & $239,513,290.00$ & $332,806,436.00$ & $9,979,511.00$ & $47,100,859.00$ \\
\hline 2005 & $2,093,628,859.00$ & $84,137,983.00$ & $526,288,967.00$ & $397,744,643.00$ & $10,339,647.00$ & $46,337,150.00$ \\
\hline 2006 & $2,182,432,083.68$ & $76,797,392.46$ & $629,596,866.35$ & $333,687,177.83$ & $7,926,235.00$ & $44,410,804.00$ \\
\hline 2007 & $2,415,649,040.74$ & $76,524,011.38$ & $760,747,361.00$ & $354,610,374.44$ & $9,417,626.00$ & $34,980,978.00$ \\
\hline 2008 & $2,282,440,394.61$ & $80,403,045.27$ & $758,780,521.32$ & $391,075,575.03$ & $7,640,304.00$ & $23,222,765.00$ \\
\hline
\end{tabular}




\begin{tabular}{lllllll}
\hline YEAR & $\begin{array}{l}\text { GAS PRODUCED } \\
\text { (MSCF) }\end{array}$ & $\begin{array}{l}\text { GAS USED AS } \\
\text { FUEL (MSCF) }\end{array}$ & $\begin{array}{l}\text { GAS SOLD TO } \\
\text { THIRD PARTY } \\
\text { (MSCF) }\end{array}$ & $\begin{array}{l}\text { GAS RE- } \\
\text { INGECTED } \\
\text { (MSCF) }\end{array}$ & $\begin{array}{l}\text { GAS TO EPCL } \\
\text { (MSCF) }\end{array}$ & $\begin{array}{l}\text { FEEDSTOCK GAS } \\
\text { FOR NGL/NGL TO } \\
\text { EPCL (MSCF) }\end{array}$ \\
\hline 2009 & $1,837,278,307.30$ & $80,573,879.69$ & $440,941,863.13$ & $409,848,717.60$ & $8,086,525.00$ & $42,401,451.00$ \\
2010 & $2,392,838,898.50$ & $72,233,896.74$ & $857,225,684.61$ & $493,309,826.14$ & $5,204,476.00$ & $25,866,822.00$ \\
2011 & $2,400,402,880.07$ & $104,541,241.41$ & $786,837,514.68$ & $348,331,140.17$ & $9,434,733.66$ & $38,607,385.00$ \\
2012 & $2,580,165,626.03$ & $115,677,106.11$ & $875,458,448.62$ & $462,875,916.15$ & $15,367,328.41$ & $47,186,521.00$ \\
2013 & $2,325,137,449$ & $128,523,560.00$ & $606,542,389.00$ & $638,506,664.00$ & $9,220,378.00$ & $56,076,709.00$ \\
\hline
\end{tabular}

\section{Appendix II}

Table 3. Gas Utilization in Nigeria 2000-2013.

\begin{tabular}{|c|c|c|c|c|c|c|}
\hline YEAR & $\begin{array}{l}\text { GAS FOR LNG } \\
\text { (MSCF) }\end{array}$ & $\begin{array}{l}\text { GAS TO NGC } \\
\text { (MSCF) }\end{array}$ & GAS LIFT (MSCF) & $\begin{array}{l}\text { GAS UTILISED } \\
\text { (MSCF) }\end{array}$ & $\begin{array}{l}\text { GAS FLARED } \\
\text { (MSCF) }\end{array}$ & $\begin{array}{l}\text { GAS } \\
\text { FLARED \% }\end{array}$ \\
\hline 2000 & $253,121,964.00$ & $52,792,960.00$ & $21,535,887.00$ & $749,652,677$ & $882,760,070$ & $55 \%$ \\
\hline 2001 & & & & $94,038,772$ & $920,905,671$ & $51 \%$ \\
\hline 2002 & $290,045,550.00$ & $89,794,378.00$ & $17,151,356.00$ & $897,789,582$ & $744,108,035$ & $45 \%$ \\
\hline 2003 & $463,380,371.00$ & $116,320,144.00$ & $19,425,784.00$ & $983,562,969$ & $846,013,629$ & $46 \%$ \\
\hline 2004 & $410,167,378.00$ & $72,758,426.00$ & $11,883,045.00$ & $1,195,742,993$ & $886,070,556$ & $43 \%$ \\
\hline 2006 & $240,915,583.15$ & & $45,436,202.11$ & $1,378,770,261$ & $799,998,368$ & $37 \%$ \\
\hline 2007 & $368,626,236.29$ & & $51,053,728.00$ & $1,655,960,315$ & $789,546,172$ & $33 \%$ \\
\hline 2008 & $331,569,374.19$ & & $58,560,235.34$ & $1,651,251,820$ & $631,188,574$ & $28 \%$ \\
\hline 2009 & $269,095,955.76$ & $21,021,894.00$ & $55,956,115.76$ & $1,327,926,402$ & $509,351,905$ & $28 \%$ \\
\hline 2010 & $167,190,148.97$ & & $169,057,005.18$ & $1,790,087,860$ & $581,568,354$ & $24 \%$ \\
\hline 2011 & $313,087,278.00$ & $101,560,670.00$ & $78,970,059.14$ & $1,781,370,022$ & $619,032,858$ & $26 \%$ \\
\hline 2012 & $329,863,143.48$ & $72,166,259.00$ & $72,904,179.09$ & $1,991,498,902$ & $588,666,724$ & $23 \%$ \\
\hline
\end{tabular}

\section{Appendix III}

Table 4. Gas Production and Flaring in Nigeria (2009-2013).

\begin{tabular}{lllll}
\hline GAS PRODUCTION AND FLARING IN NIGERIA (2009 - 2013) & & & \\
\hline Year & Company Type & Gas Produced & Gas Flared & Gas Flared \% \\
\hline 2009 & Joint Venture Companies (JVC) & $1,632,787,949.30$ & $418,448,895.45$ & $25.63 \%$ \\
& Production Sharing Contract (PSC) & $183,326,704.00$ & $70,151,925.90$ & $38.27 \%$ \\
& Service Contract (SC) & $9,948,654.00$ & $9,891,084.00$ & $99.42 \%$ \\
& Sole Risk/Independent (SR/I) & $11,215,000.00$ & $10,860,000.00$ & $96.83 \%$ \\
2010 & Joint Venture Companies (JVC) & $2,185,633,370.70$ & $492,245,933.25$ & $22.52 \%$ \\
& Production Sharing Contract (PSC) & $189,979,051.80$ & $72,300,238.35$ & $38.06 \%$ \\
& Service Contract (SC) & $6,713,476.00$ & $6,531,333.26$ & $97.29 \%$ \\
& Sole Risk/Independent (SR/I) & $10,513,000.00$ & $10,490,848.99$ & $99.79 \%$ \\
& Joint Venture Companies (JVC) & $2,159,449,794.01$ & $514,779,615.63$ & $23.84 \%$ \\
& Production Sharing Contract (PSC) & $171,941,816.36$ & $62,390,495.76$ & $36.29 \%$ \\
& Service Contract (SC) & $9,663,197.00$ & $9,356,457.00$ & $96.83 \%$ \\
& Sole Risk/Independent (SR/I) & $57,943,988.80$ & $32,431,609.05$ & $55.97 \%$ \\
& Marginal Fields (MF) & $1,404,083.90$ & $74,680.57$ & $5.32 \%$ \\
& Joint Venture Companies (JVC) & $2,192,569,547.89$ & $474,322,797.86$ & $21.63 \%$ \\
& Production Sharing Contract (PSC) & $267,131,037.43$ & $68,909,872.63$ & $25.80 \%$ \\
& Service Contract (SC) & $9,312,369.00$ & $9,266,199.00$ & $99.50 \%$ \\
& Sole Risk/Independent (SR/I) & $108,955,737.50$ & $34,240,624.69$ & $31 \%$ \\
& Marginal Fields (MF) & $2,196,934.21$ & $1,927,230.00$ & $88 \%$ \\
& Joint Venture Companies (JVC) & $1,815,824,476$ & $234,440,620$ & $13 \%$ \\
& Production Sharing Contract (PSC) & $385,890,802$ & $68,715,537$ & $18 \%$ \\
& Service Contract (SC) & $2,518,197$ & $2,506,607$ & $100 \%$ \\
& Sole Risk/Independent (SR/I) & $108,748,690$ & $94,314,103$ & $87 \%$ \\
& Marginal Fields (MF) & $12,155,284$ & $9,334,564$ & $77 \%$ \\
\hline \multirow{2}{*}{2013} & & & & \\
\end{tabular}

Source: NNPC Annual Statistical Bulletin, 2009-2013. 


\section{References}

[1] http://go.worldbank.org/016TLXI7N0.

[2] Ugwuoke P. E., Agwunobi U. C., Aliyu A. O. (2012). Renewable Energy as a Climate Change Mitigation Strategy in Nigeria. International Journal of Environmental Sciences, Volume 3, No 1, 11-19.

[3] IPCC, 2014: Summary for Policymakers, In: Climate Change 2014, Mitigation of Climate Change. Contribution of Working Group III to the Fifth Assessment Report of the Intergovernmental Panel on Climate Change [Edenhofer, O., R. Pichs-Madruga, Y. Sokona, E. Farahani, S. Kadner, K. Seyboth, A. Adler, I. Baum, S. Brunner, P. Eickemeier, B. Kriemann, J. Savolainen, S. Schlömer, C. von Stechow, T. Zwickel and J. C. Minx (eds.)]. Cambridge University Press, Cambridge, United Kingdom and New York, NY, USA

[4] Haung B. J., Jiang C. B. and Fu F. L. (1985). Ejector Performance Characteristics and Design Analysis of Jet Refrigeration System. ASME Journal of Engineering for Gas Turbines and Power, Vol. 107,* 792-802.

[5] Iamashita, E. K., Galaxe, F. and Arica, J. (April,2008). A Planning Model for Offshore Natural Gas Transmission. Pesquisa Operacional. Janeiro.

[6] Devold, H. (2006) An Introduction to Oil and Gas. Oil and Gas Production Handbook, ABB, Oslo .

[7] Kamal, B., John, G., \& Hasan, I. (2008, January 14). Supersonic Ejector Captures, Reinjects Leaked Vent Gases. Oil \& Gas Journal, 54.

[8] NNPC, (2000-2013). Annual Statistical Bulletin.

[9] Sarshar, M. M., (April, 1999). The Esso Energy Award Lecture, 1998, Boosting Production from Low-Pressure Oil and Gas Fields: A Revolution in Hydrocarbon Production. The Royal Society, London. Vol. 357, 921 - 941. 